Çukurova Üniversitesi Mühendislik Fakültesi Dergisi, 36(3), ss. 815-825, Eylül 2021

Cukurova University Journal of the Faculty of Engineering, 36(3), pp. 815-825, September 2021

\title{
Flow and Mechanical Characteristics of a Modified Naca Wing Geometry
}

\author{
Mustafa Murat YAVUZ ${ }^{* 1}$ \\ ${ }^{1} \dot{I}_{z m i r}$ Democracy University, Faculty of Engineering, Mechanical Engineering Department, Izmir
}

Geliş tarihi: 09.06.2021 Kabul tarihi: 13.09.2021

\begin{abstract}
The flying ability is directly related to the structure of the wing geometry. The wing structure is designed differently according to each working conditions. In this study, a free-formed airfoil section was designed and the behaviour of the model under the influence of flow was investigated in terms of diving and takeoff angles. Computational fluid dynamics method was used in the analysis. The sensitivity of the method was checked by comparing the solution of a NACA airfoil section with the experimental results in the literature and its usability in the study was accepted. Also, in the study, the wing geometry was modelled as 3D and layered, and its mechanical properties were examined. The designed airfoil has more dominant flow structure in the lift direction. Non-symmetrical airfoil causes unsymmetrical Cl-Cd distribution. As a result of the wing structure being more dominant in lift, it was observed that the deformation and stress results of the positive angle of attack were higher than the negative results. Depending on the angle of attack, the pressure and flow effects on the wing caused a higher bending-torsion effect and increased the stresses in the fixation region of the wing. The lowest deformation and average stresses occurred at $-4^{\circ}$ angle of attack. The results are discussed as a result of flow and mechanical findings.
\end{abstract}

Keywords: Angle of attack, CFD, Deformation, Structural analysis

\section{Değiştirilmiş Bir Naca Kanat Geometrisinin Akış ve Mekanik Özellikleri}

$\ddot{\mathbf{O z}}$

Uçma yeteneği doğrudan kanat geometrisinin yapısı ile ilgilidir. Kanat yapısı her çalışma koşuluna göre farklı tasarlanmaktadır. Bu çalışmada, serbest biçimli bir kanat profili kesiti tasarlanmış ve modelin akış etkisi altındaki davranışı dalış ve kalkış açıları açısından incelenmiştir. Analizde hesaplamalı akışkanlar dinamiği yöntemi kullanılmıştır. Yöntemin duyarlılığı, bir NACA kanat profili kesitinin çözümü literatürdeki deneysel sonuçlarla karşılaştırılarak kontrol edilmiş ve çalışmada kullanılabilirliği kabul edilmiştir. Ayrıca çalışmada kanat geometrisi 3 boyutlu ve katmanlı olarak modellenmiş ve mekanik özellikleri incelenmiştir. Tasarlanan kanat profili, kaldırma yönünde daha baskın akış yapısına sahiptir. Simetrik olmayan kanat profili, simetrik olmayan Cl-Cd dağılımına neden olur. Kanat yapısının kaldırmada daha baskın olması sonucunda, pozitif hücum açısının deformasyon ve gerilme sonuçları negatif sonuçlara göre daha fazla olduğu gözlemlendi. Hücum açısına bağlı olarak kanat üzerindeki basınç ve akış etkileri daha yüksek eğilme-burulma etkisine neden olmuş ve kanadın sabitleme bölgesinde gerilmeleri arttırmıştır. En düşük deformasyon ve ortalama gerilmeler $-4^{\circ}$ hücum açısında meydana gelmiştir. Sonuçlar akış ve mekanik bulgular neticesinde tartışılmıştır.

Anahtar Kelimeler: Hücum açısı, HAD, Deformasyon, Yapısal analiz

"Sorumlu yazar (Corresponding author): Mustafa Murat YAVUZ,murat.yavuz@idu.edu.tr 


\section{INTRODUCTION}

Wings are the main component of aircraft, and the lifting property is one of the critical design parameters for them. There are a wide variety of wing types, and each wing design exhibits its unique flow behaviour, and their flight performance is different. That is why it's constantly being developed. The wings are operated in complex working conditions that includes aerodynamic, aeroelastic and body forces. Different wings are designed for providing optimum requirements and most of them are classified with NACA airfoil structure. Air and water channel flow experiment and computational fluid dynamics (CFD) are widely used for the designing process. In literature, some modified wing sections and NACA airfoil wing flow characteristic studies are available. A 2D NACA 0012 wing section is [1] investigated by using CFD and effect of angle of attack is searched between $0^{\circ}$ and $40^{\circ}$. Flow separations and transition are captured, and vortex shedding are observed. Another NACA 0012 wing study [2] includes design modifications to increase lift-drag ratio by using CFD. A validation study is initially applied, and flaps and slots are included with different angles or locations. A NACA 0012 flapped airfoil [3] is considered with the effect of hinge position and suction effect. Shear stress transport $k-\omega$ turbulence model is used in the analysis. The usage of perpendicular suction and the movement of hinge position to trailing edge of the airfoil increase the lift coefficient. Kadhem and Hussein [4] investigate piezoelectric active suppressions to decrease vibrations and flutter of composite NACA 0012 wing airfoil which includes two different composites; glass-fiber random matt and woven (0/90 orientation) glassfiber. Perpendicular and tangential suctions increase lift-drag ratio $35.8 \%$ and $25.1 \%$ higher than the case without suction and lift coefficient increases when hinge come closer to trailing edge of the airfoil. Composite woven wing has better resistance performance than other composite random wing. More studies on NACA 0012 like shape optimization [5], the effect of porosity on the performance [6] and transonic flutter behaviour of aeroelastic model [7] are available. Yan [8] studies on dynamic flutter derivatives rather than static ones to predict wing flutter speed of NACA 0010, 0012, 0014 and 0018 aerofoils by using aeroelastic stiffness and damping equation. Wings have a wingspan of $0.36 \mathrm{~m}$, a chord length of 0.16 $\mathrm{m}$ and an aspect ratio of $4.5 . \mathrm{Cl}$ and $\mathrm{Cm}$ dynamic values are $10 \%-40 \%$ higher than static ones for all models. Aerodynamic coefficients boundary layer of a 2D NACA 43013 airfoil [9] is investigated under incompressible viscous flow by using ANSYS Fluent software. The results are compared with suitable data and compatible results have been achieved. Another wing type; NACA 4412 airfoil [10] is designed with aerodynamic coefficients by using CFD. Flow separation and reattach region of flow are considered in the study. A leading-edge modification to NACA 4412 wing [11] is applied for increasing aerodynamic performance. When leading-edge is designed with curved shape rather than rectangular, flow performance has been increased. Flutter behaviour and dynamic instability of NACA 4412 wing section [12] is investigated by using numerical methods. The study results are validated by a compared experimental result and critical flutter speed is determined. Gore et al. [13] investigate NACA 4412 aerofoil under various angle of attack $(0,8,16,20,25,27$ degrees) at a constant Mach number of 0.6 that maximum lift has been achieved at angle of attack of $25^{\circ}$ and it is larger than drag forces. A NACA 0015 wing has been [14] investigated with semi-span aspect ratios of 2, 3 and 4 that changes unsteady lift behaviour directly. Cavitating turbulent flow [15] around a NACA 16012 wing is investigated by using large eddy simulation (LES) that provides the vortices to be seen easily. Pressure coefficient increases under the effect of the horseshoe vortex at downstream. Aerodynamic performance [16] is investigated by using CFD for a NACA 23012 wing. A validation case is prepared and compared with a suitable wind tunnel test result. Stagnation points are determined for putting a stall warning device. Effect of angle of attack [17] on lift, drag and pressure distribution is researched for a NACA 4415 wing which has a chord length of $200 \mathrm{~mm}$, span of length $450 \mathrm{~mm}$ and leading edge radius of $4.96 \mathrm{~mm}$. Flow separation is detected at low angle of attack from $-6^{\circ}$ to $0^{\circ}$ and full separation is 
observed at high angle of attack from $12^{\circ}$ to $18^{\circ}$ at different speeds. Delaying and controlling the flow separation over NACA 2415 airfoil [18] are investigated to find the best slot location. The location at 0.3 to 0.6 of the airfoil chord length is the most effective slot locations for applying suction and stall angle is increased from $10^{\circ}$ to $16^{\circ}$ by applying slot modification. Flutter is an important phenomenon and affect aeroelastic stability which includes aerodynamic, elastic and inertial forces and Eken [19] uses thin walled composite beam theory to investigate three different NACA 4-digit-series (NACA 0009, NACA 0015, NACA 0021). The lowest frequency is found at NACA 0021 and the highest is found at NACA 0009 wing. The frequency can be modified if composite structures are used. Viglietti et al. [20] investigate variable angle-tow composites to improve dynamic behaviour of simple beam and complex wing structures. Fibre paths can be used to prevent undesired effects of bending and torsion frequencies. Wang et al. [21] investigated a single NACA airfoil aerodynamic excitation induced forced response. The study shows that the vibration depends on both central frequency of excitation and Reynold number. Bogrekci et al. [22] investigate structural and modal properties of NACA 66-206 wing section under lift and weight forces by using Ansys Workbench static structural and modal analysis tools. Aluminium 6061, carbon fiber and strong unidirectional epoxy glass are selected as wing materials and three different motion velocities 10, 50 and $100 \mathrm{~m} / \mathrm{s}$ are considered. The maximum values of deformation are $2.28 \mathrm{~mm}$ for aluminium, $0.16 \mathrm{~mm}$ for carbon fiber and $7.71 \mathrm{~mm}$ for epoxy glass at the highest velocity. Carbon fiber material is better than aluminium and epoxy glass with respect to high natural frequency values and the lowest weight force. Kulshreshtha et al. [23] compared lift and drag coefficient of NACA 2412, 2414 and 2415 sections at different angle of attack for constant air velocity by using CFD. Aerodynamic analysis [24] was carried out for the NACA 2412 airfoil section aircraft wing. Pressure and velocity contours were given as flow results, and the stresses on the wing as a result of their effects are shown. In the study of aeroelastic behaviour, different wing and conditions were tried to be optimized. The researchers [25-26] who examined the aeroelastic behaviour of a seamless wing by considering different camber sections, determined the appropriate design criteria. Newman et al. [27] studied the aeroelastic behaviour of a wing geometry under subsonic and supersonic flow conditions. While the unstructured Euler model was created in flow condition, it was used in less element models with structural mesh in the finite element model. Alyaak and Pendleton [28] created a finite element model of the tailless lambda wing and studied its aeroelasticity and determined the optimum conditions considering the wing's weight. Hou and Satyanarayana [29] prepared a remeshing option to be used in the structural and numerical analysis of the aircraft wing under the influence of flow and facilitated the tracking of deformation. Reich et al. [30] optimize structural structure of embedded antenna of a joined wing sensorcraft using control surface analyses. Zink et al. [31] investigated the aeroelastic response of a flexible wing by including inaccuracies in aerodynamic loads and redesigned the wing for this condition. Unlike linear loading, a slightly heavier but structurally stronger airfoil was achieved in designs. Guo [32] optimized a wing's weight and aeroelastic response together and was able to achieve similar aeroelastic behaviour with $40 \%$ less weight without the use of reinforcements. Stanford [33] studied the aeroservoelastic response of one edge of the wings prepared with various camber shapes and focused on minimizing weight while avoiding buckling, hinge moments, flutter. Szollosi and Baranyi [34] examined the control performance for a 2D airfoil with 3 degrees of freedom and provided performance improvement by using different models in their parametric analysis. Apart from this classification, different wing models are examined. In this study, an airfoil section that is not classified NACA type is designed and its aerodynamic and aeroelastic properties are investigated.

\section{COMPUTATIONAL METHOD AND MODELLING}

Computer-aided numerical methods were used to examine the properties of the NACA airfoil 
profile. The CFD method was used to examine the flow conditions and the FEM method to examine the mechanical properties. Before examining the designed airfoil, a NACA 0012 model whose results are available in the literature was examined to determine the accuracy of the analyses. 2D NACA 0012 airfoil model prepared for CFD analysis is shown in Figure 1. In the study using air as fluid, the angle of attack was taken as $0^{\circ}$ and the Reynolds number was determined to be $6,000,000$. Sparlat-Allmaras turbulence model has been used due to its smooth and symmetrical airfoil shape. In the same conditions, while the friction coefficient was 0.006 in the literature study [35], it was obtained as 0.00642 in this study.
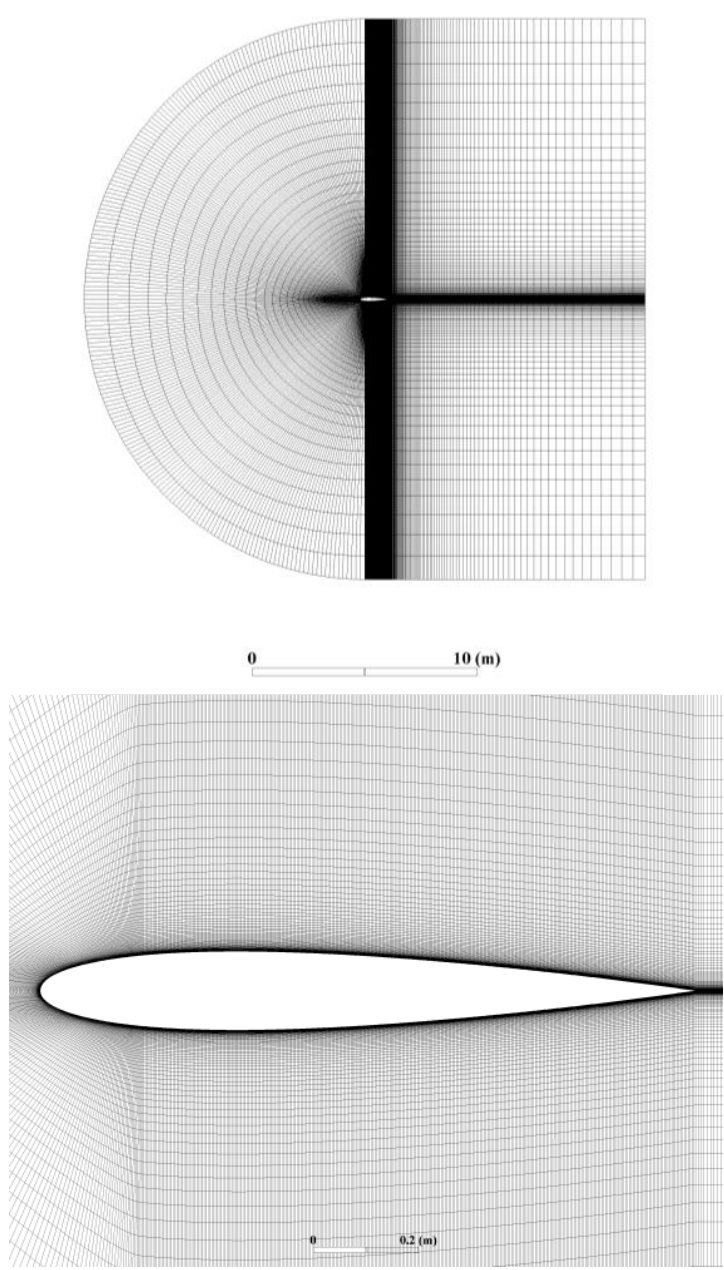

Figure 1. CFD domain of 2D NACA 0012 model
The specially created new NACA airfoil profile is shown in Figure 2. In addition to the 2D cross section geometry model, 3D wing model was created. Point coordinates of the airfoil geometry in the plane are available in appendix. For the airfoil geometry, 2D flow analysis was performed and the flow characteristics around the airfoil was visualized. In addition, a 3D wing model consisting of two nested layers was examined under flow conditions and flow properties (velocity and pressure effects) were obtained for mechanical analysis. Afterwards, 2-layer materials were defined for the mechanical solution and static analysis was performed. The wing root is defined as a fixed support. The profile on the inside $\left(\mathrm{W}_{\text {in }}\right)$ is defined as epoxy e-glass ud and the profile on the outside $\left(\mathrm{W}_{\text {out }}\right)$ as epoxy carbon woven (230 $\mathrm{GPa}$ ) prepreg. Wing sections are $2 \mathrm{~mm}$ thick. Material properties are shown in table 1. $\rho$ is the density, $\mathrm{E}$ is the modulus of elasticity and $v$ is the Poisson ratio of the materials. Gravitational effects are neglected.
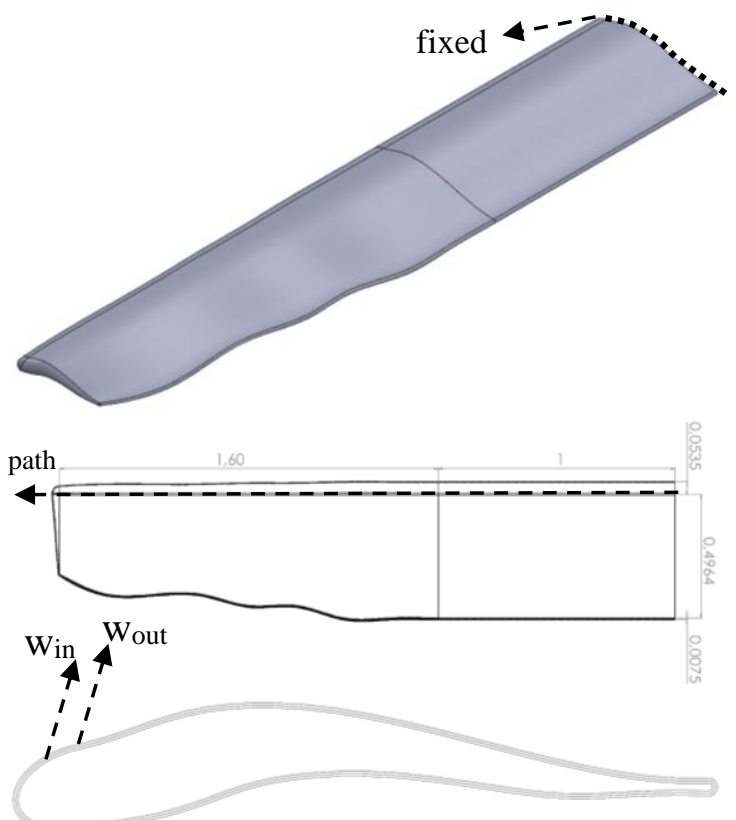

Figure 2. Isometric view of 3D model of airfoil and section view

The curved leading edge is created by using different cross-section dimensions in the direction 
of the airfoil. In order to reduce the effect of weight at the airfoil tip and the resulting bending moment, the 3D airfoil has three airfoil profile reductions of $0.8,0.8$ and 0.7 times in $1.6 \mathrm{~m}, 2.0 \mathrm{~m}$ and $2.6 \mathrm{~m}$ dimensions, respectively. A similar model [36] is also found in the literature on curved and straight wing edge analysis.

Table 1. Used material properties in wing-cross sections

\begin{tabular}{|c|c|c|}
\hline & $\begin{array}{c}\text { Epoxy Carbon } \\
\text { Woven (230 GPa) } \\
\text { Prepreg }\end{array}$ & $\begin{array}{c}\text { Epoxy E-Glass } \\
\text { UD }\end{array}$ \\
\hline $\boldsymbol{\rho}$ & $1420 \mathrm{~kg} / \mathrm{m}^{3}$ & $2000 \mathrm{~kg} / \mathrm{m}^{3}$ \\
\hline $\mathbf{E}_{\mathbf{x}}$ & $61.34 \mathrm{GPa}$ & $45 \mathrm{GPa}$ \\
\hline $\mathbf{E}_{\mathbf{y}}$ & $61.34 \mathrm{GPa}$ & $10 \mathrm{GPa}$ \\
\hline $\mathbf{E}_{\mathbf{z}}$ & $6.9 \mathrm{GPa}$ & $10 \mathrm{GPa}$ \\
\hline $\boldsymbol{v}_{\mathbf{x y}}$ & 0.04 & 0.3 \\
\hline $\boldsymbol{v}_{\mathbf{y z}}$ & 0.3 & 0.4 \\
\hline $\boldsymbol{v}_{\mathbf{x z}}$ & 0.3 & 0.3 \\
\hline
\end{tabular}
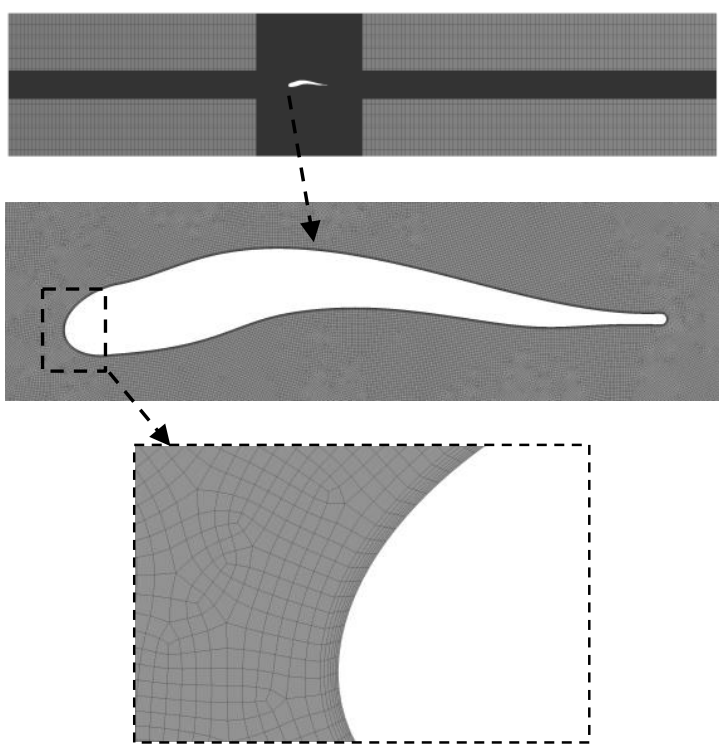

Figure 3. CFD domain and applied boundary conditions

A 2D CFD model was created to observe the flow behaviour and is shown in Figure 3. In the model, a layered grid model was created for the wing surface. A magnified view has also been added to show the grid structure around the wing. Standard properties of water were used as fluid $\left(\right.$ density $=998.2 \mathrm{~kg} / \mathrm{m}^{3}$, viscosity $=0.001003 \mathrm{~kg} / \mathrm{ms}$ ) and flow solution was made for Reynolds number 10000. K-epsilon turbulence model was used to solve the partial derivatives in momentum eq'n, which is widely used CFD model. The continuity and momentum (Navier-Stokes) equation [37] for the solution structure are shown below;

$\frac{\partial \rho}{\partial t}+\frac{\partial}{\partial x_{i}}\left(\rho u_{i}\right)=0$

$\frac{\partial}{\partial t}\left(\rho u_{i}\right)+\frac{\partial}{\partial x_{i}}\left(\rho u_{i} u_{j}\right)=\frac{\partial \rho}{\partial x_{i}}+\frac{\partial}{\partial x_{j}}\left[\mu\left(\frac{\partial u_{i}}{\partial x_{j}}+\frac{\partial u_{j}}{\partial x_{i}}-\right.\right.$

$\left.\left.\frac{2}{3} \delta_{i j} \frac{\partial u_{1}}{\partial x_{1}}\right)\right]+\frac{\partial}{\partial x_{j}}\left(-\rho \overline{x_{i}^{\prime} x_{j}^{\prime}}\right)$

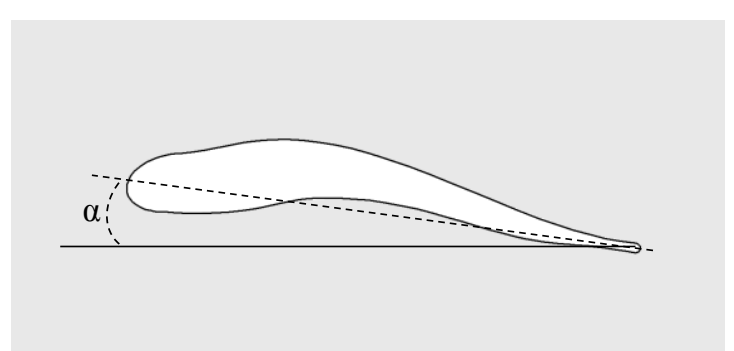

Figure 4. The angle of attack $(\alpha)$ on the airfoil

The angle of attack formed between the wing centerline passing through the wing tips and the horizontal plane was shown in Figure 4.

\section{RESULTS AND DISCUSSION}

The pressure results around the airfoil are shown in Figure 5 for different angles of attack. The pressure results are widely given in literature [3839] and provide important information for lifting and drag behaviour. The freely modelled airfoil geometry is non-symmetrical, resulting in a notable difference in pressure locations. At $-8^{\circ}$ of attack angle, the upper surface of the airfoil front appears to be the high-pressure area and the lower surface as the lowest pressure area. This pressure profile has a positive effect on the diving condition of the airfoil. In the rest of the lower surface of the airfoil, the pressure is stagnant, and the effect is low. There is a low-pressure zone in the middle of the upper surface of the airfoil. This pressure zone will raise the airfoil evenly. 


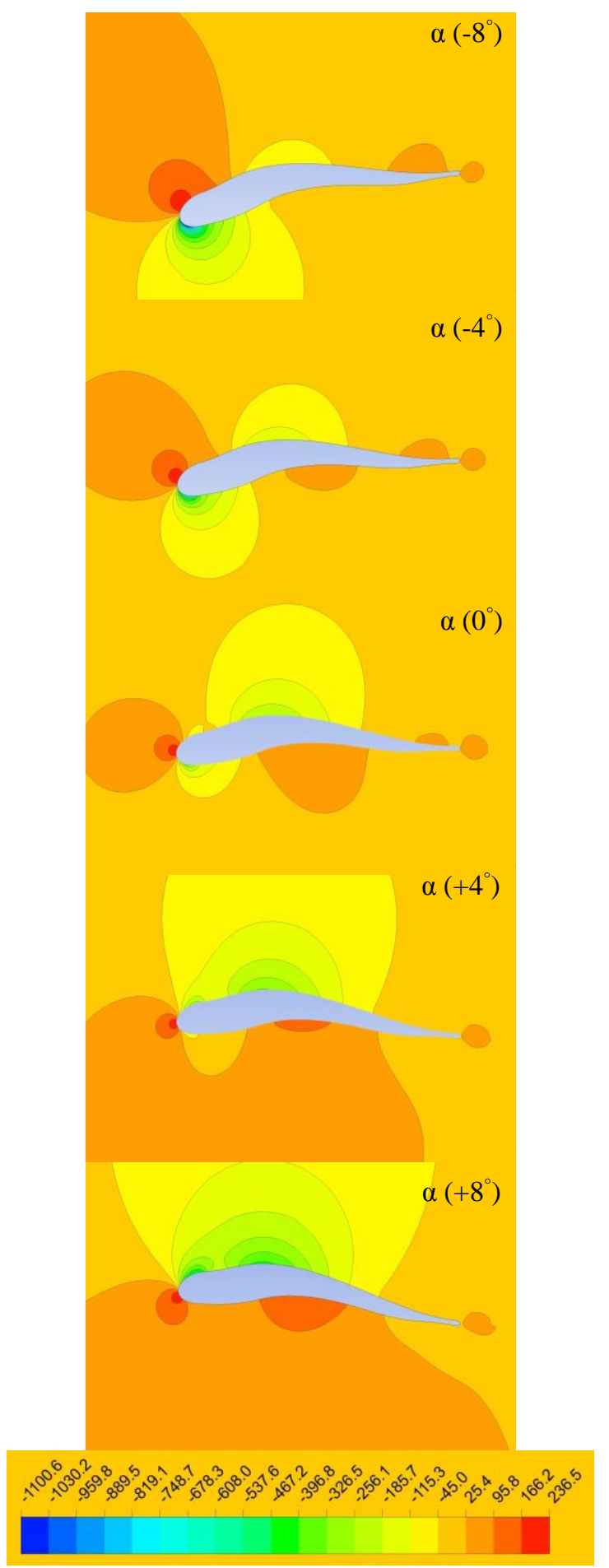

Figure 5. Pressure contours of wing profile under different angles of attack
In addition, the high pressure formed at the rear end of the upper surface is in a structure to reduce the excessive diving moment that may occur in the airfoil. Pressure profile at $-4^{\circ}$ is similar to $-8^{\circ}$. However, positive and negative pressure values started to decrease. The negative pressure profile in the middle of the upper surface of the airfoil has started to grow. The moment structure that can turn the airfoil towards the dive direction is reduced. The high pressure on the upper surface of the airfoil tip at $0^{\circ}$ has come right in front of the airfoil. The low-pressure profile under the airfoil tip is reduced. The negative pressure region formed in the middle of the upper surface of the airfoil has increased. The pressure distribution exhibited in the aircraft airfoil profiles was similarly obtained. At the angle of attack adjusted for $+4^{\circ}$ upward climb, the negative pressure under the airfoil disappeared and formed on the upper surface of the airfoil in a large area. A highpressure profile has occurred under the airfoil. At $+8^{\circ}$, these pressure distribution values have grown. The low pressure on the upper surface of the airfoil has increased its effect. There was no dominant pressure difference on the upper and lower surfaces of the tail part of the airfoil. In this region, a flap should be designed on the tail part in order to benefit from airfoil climbing or diving situations.

The velocity profile formed around the airfoil is shown in Figure 6. The free-stream velocity, which does not interact with the airfoil surface, appears on the contours as $0.67 \mathrm{~m} / \mathrm{s}$. The distributions of the velocity profiles are inversely proportional to the pressure profiles. High velocity profile is seen in low pressure areas. In diving condition, there is a low velocity profile in the front upper surface of the airfoil and in the middle of the lower surface of the airfoil. As the angle of attack increased, the velocity profile on the upper surface of the airfoil began to accelerate. The velocity under the airfoil was lower than the free-stream velocity. A flow profile suitable for the airfoil characteristic is observed. 


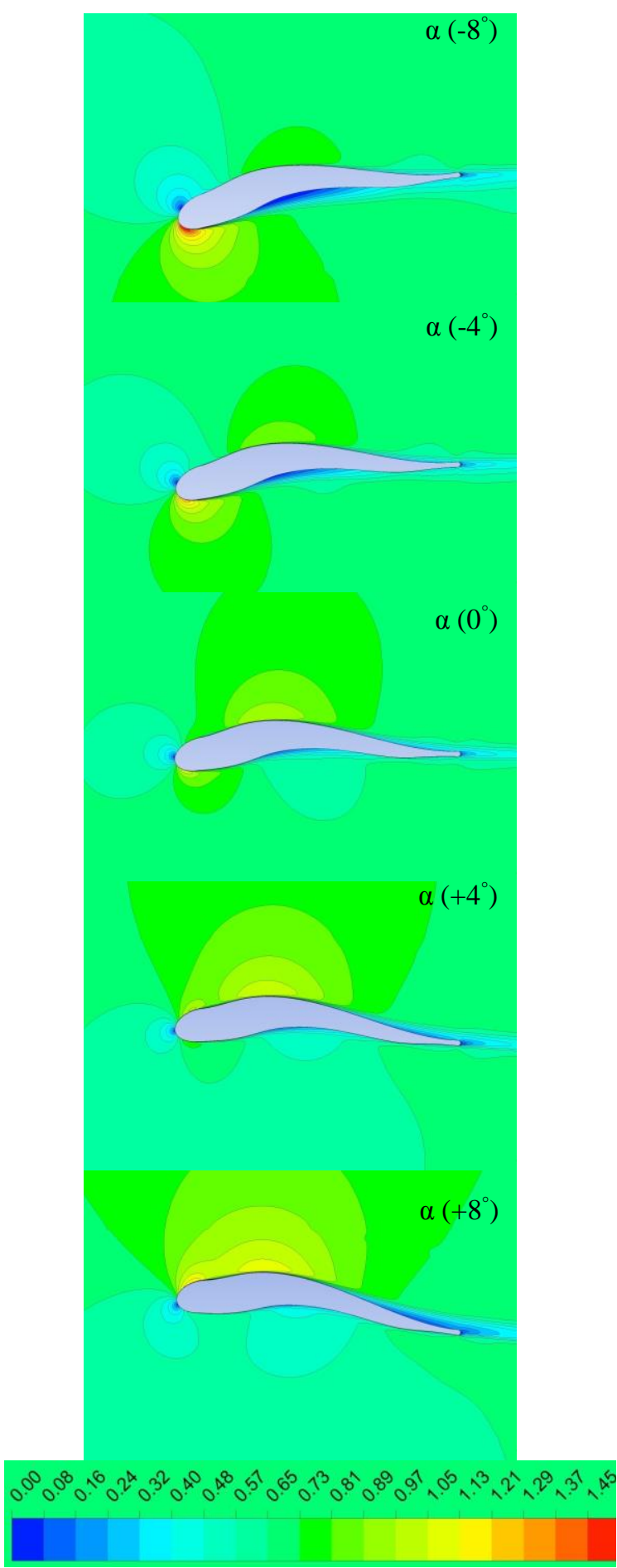

Figure 6. Velocity contours around the airfoil under different angle of attack
The variation of the lift coefficient with respect to the angle of attack where the airfoil is positioned relative to the free flow direction is shown in Figure 7. Accordingly, the drag coefficient is also given. A positive lift coefficient at $0^{\circ}$ angle of attack indicates that the airfoil is more dominant in the lift direction. The lift coefficient was obtained as 0.65 at $+8^{\circ}$ angle of attack. In the lift-drag interaction, the best lift effect is obtained at the positive angle of attack and the best drag effect is obtained at the negative angle of attack (in the diving state). This is a desirable condition for both conditions. The fact that the airfoil is not symmetrical has created an unsymmetrical distribution in the $\mathrm{Cl}-\mathrm{Cd}$ graph. A symmetrical distribution is more common in symmetrical wing profiles [35].

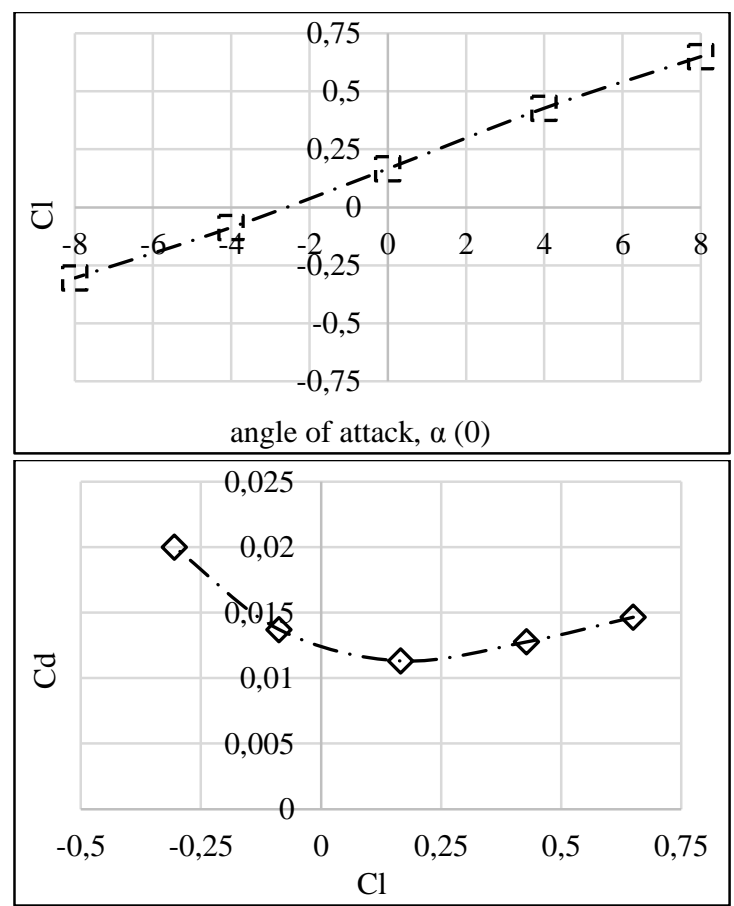

Figure 7. $\mathrm{Cl}$ vs angle of attack and $\mathrm{Cd}$ vs $\mathrm{Cl}$ graphs

The vertical deflections and stresses occurring in the wing are taken from a path defined at the wing tip edge against the flow. The unsymmetrical airfoil wing has a significant effect on vertical deflection and shown in Figure 8. The fact that the 
fluid pressure created is not symmetrical and that the wing is in an angled position relative to the vertical-horizontal axis has affected the formation of vertical deflection. The highest deflection profile occurred when the angle of attack was $+8^{\circ}$. The deflection profile is upwards, and the deflection increase slows after 1.8 meters. $+4^{\circ}$ result has positive vertical deflection, and this deformation structure is in linear increase structure. When the angle of attack is $0^{\circ}$, there is very little vertical deflection in the upward direction. Vertical deflection is negligible as a result of $-4^{\circ}$, where the wing attack angle becomes diving. There is a vertical deflection in the parabolic structure formed in the negative direction as a result of $-8^{\circ}$. Here, when the results of $+4^{\circ}$ and $-4^{\circ}$ and $+8^{\circ}$ and $-8^{\circ}$ are compared with each other, it is seen that the wing exhibits a more dominant deformation behaviour in the upward direction. Negative deformation behaviour is less.

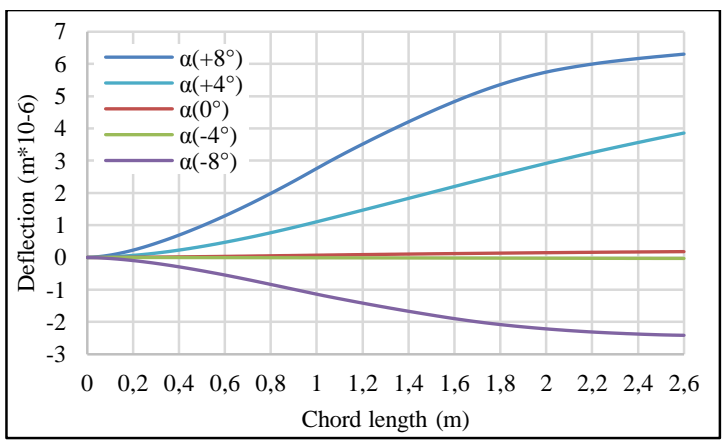

Figure 8. Vertical deflection of the wing

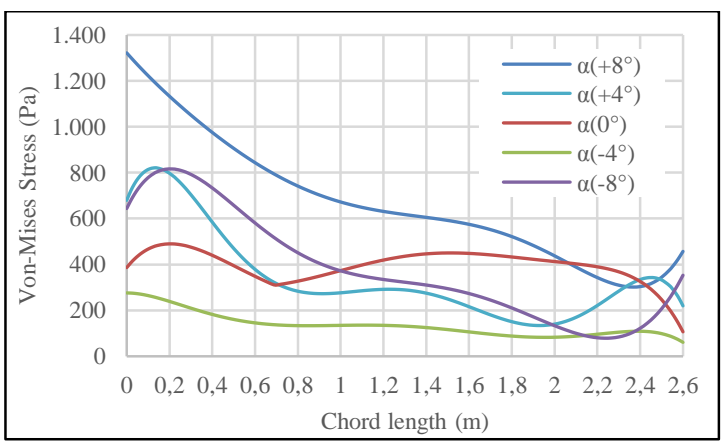

Figure 9. Stress formations at the wing front edge

The stresses occurring in the front of the wing are shown in Figure 9. At $-4^{\circ}$ angle of attack where the deformation is the least, the stress values are the lowest and the sudden changes in the values are the least. The stress value is the highest as a result of $+8^{\circ}$, where the highest deformation occurs. Its values decrease towards the wing tip. At $+4^{\circ}$ and $8^{\circ}$ results, the deformation values are similar and the highest stress values are almost the same. Although the deformation is very small at $0^{\circ}$ angle of attack, the stresses are around $400 \mathrm{MPa}$ and generally do not show a decreasing behaviour towards the wing tip. There is a sudden increase in the results of $+8^{\circ}$ and $-8^{\circ}$ at the wing tip. This behaviour is not observed in other attack angles.

\section{CONCLUSION}

In this study, a free form airfoil section, which is not found in the standards, was created and its flow and mechanical behaviour were investigated. Computer aided numerical analysis methods were used in the study. Considering the positive and negative angle of attack results for the wing in the study,

The designed airfoil is non-symmetrical, resulting in a notable difference in pressure formations and unsymmetrical distribution is observed in the Cl-Cd graph.

$>$ The high pressure on the upper surface of the airfoil tip has come right in front of the airfoil. The low-pressure profile under the airfoil tip is reduced at $0^{\circ}$ and positive lift coefficient is observed which indicates that the airfoil has more dominant behaviour in the lift.

$>$ At the angle of attack adjusted for $+4^{\circ}$ upward climb, the negative pressure under the airfoil disappeared and formed on the upper surface of the airfoil in a large area.

$>$ The negative and positive pressure profiles formed on the upper and lower surfaces of the wing cover a smooth closed area. This allows especially low velocity profile to broadcast in this closed area.

$>$ In the lift-drag interaction, the best lift effect is obtained at the positive angle of attack and the best drag effect is obtained at the negative angle of attack (in the diving state).

$>$ The stress value is the highest as a result of $+8^{\circ}$, where the highest deformation occurs. 
Contrary to the vertical deformation in the wing, the fact that the stress behaviour does not exhibit a uniform distribution and a certain characteristic according to the angle of attack allows more examination in the geometric design.

$>$ There was no dominant pressure difference on the upper and lower surfaces of the tail part of the airfoil. In this region, a flap should be designed on the tail part in order to benefit from airfoil climbing or diving situations.

\section{REFERENCES}

1. Zakaria, M.Y., Ibrahim, M.M., Ragab, S., Hajj, M.R., 2018. A Computational Study of Vortex Shedding from a NACA-0012 Airfoil at High Angles of Attack. International Journal of Aerodynamics, 6(1), 1-17.

2. Rao, T.S., Mahapatra, T., Mangavelli, S.C., 2018. Enhancement of Lift-drag Characteristics of NACA 0012. Materials Today: Proceedings, 5(2), 5328-5337.

3. Fatahian, E., Nichkoohi, A.L., Salarian, H., Khaleghinia, J., 2020. Effects of the Hinge Position and Suction on Flow Separation and Aerodynamic Performance of the NACA 0012 Airfoil. Journal of the Brazilian Society of Mechanical Sciences and Engineering, 42(86).

4. Kadhem, H.A., Hussein, A.A., 2019. The Effect of Wind Velocity on the Suppression of Composite Wing Airfoil NACA 0012. AlKhwarizmi Engineering Journal, 15(3), 38- 44.

5. Yu, Y., Lyu, Z., Xu, Z., Martins, J.R.R.A., 2018. On the Influence of Optimization Algorithm and Initial Design on Wing Aerodynamic Shape Optimization. Aerospace Science and Technology, 75, 183-199.

6. Hanna, Y.G.T., Spedding, G.R., Aerodynamic Performance Improvements Due to Porosity in Wings at Moderate Re. AIAA Aviation 2019 Forum, 17-21 June 2019, Dallas, Texas.

7. Stanford, B.K., Jocobson, K.E., Massey, S.J., Transonic Aeroelastic Modeling of the NACA 0012 Benchmark Wing. AIAA Aviation 2020 Forum, June 15-19, 2020, Virtual Event, Session: Aerodynamic-Structural Dynamics Interaction, AIAA, 2020-2716.
8. Yan, B.K., 2018. Flutter Analysis of a Flexibly Supported Wing. Doctor of Philosophy Thesis, Faculty of Mechanical Engineering, Universiti Teknologi Malaysia, January 2018.

9. Hasnaoui, M., Naamane, A., Akhmari, H., 2019. Asymptotic Modeling the Aerodynamic Coefficients of the NACA Airfoil. Modelling, Measurement and Control B, 88(2-4), 58-66.

10. Körpe, D.S., Kanat, Ö.Ö., Oktay, T., 2019. The Effects of Initial y plus: Numerical Analysis of 3D NACA 4412 Wing Using $\gamma-\operatorname{Re} \theta$ SST Turbulence Model. European Journal of Science and Technology, 17, 692-702.

11. Kumar, B.R., 2019. Enhancing Aerodynamic Performance of NACA 4412 Aircraft Wing Using Leading Edge Modification. Wind and Structures, 29(4), 271-277.

12. Halima, Z., Djilali, B., 2018. Aeroelastic Analysis of an Aircraft Wing Type NACA 4412 with Reduced Scale. International Journal of Modeling and Optimization, 8(4), 241-245.

13. Gore, K., Gote, A., Govale, A., Kanawade, A., Humane, S., 2018. Aerodynamic Analysis of Aircraft Wings Using CFD. International Research Journal of Engineering and Technology (IRJET), 5(6), 639-644.

14. Gloutak, D.A., Farnsworth, J.A., 2020. Characteristic Wing Measurements of a NACA 0015 in Steady and Unsteady Surging Wind Tunnel Flow. AIAA 2020-1558 Session: Special Session: Surging and Surging/Pitching Aerodynamics II.

15. Movahedian, A., Pasandidehfard, M., Roohi, E., 2019. LES Investigation of Sheet-Cloud Cavitation around a 3-D Twisted Wing with a NACA 16012 Hydrofoil. Ocean Engineering, 192(106547), 1-13.

16. Dent, J., Robson, J., Basso, A., Ellin, A., Prakash, A., Hamad, F., 2019. Computational Study of Aerodynamic Performance and Flow Structure Around NACA 23012 Wing. International Journal of Aerodynamics (Accepted/In press)

17. Ismail, N.A., Kaisan, M.U., Balogun, M.B., Abdullahi, M.B., Faru, F.T., Ibrahim, I.U., 2020. Effect of Angle of Attack on Lift, Drag, Pitching Moment and Pressure Distribution of NACA 4415 Wing. Journal of Science Technology and Education, 8(1), 31-44. 
18. Fatahian, E., Nichkoohi, A.L., Fatahian, H., 2019. Numerical Study of the Effect of Suction at a Compressible and High Reynolds Number Flow to Control the Flow Separation Over NACA 2415 Airfoil. Progress in Computational Fluid Dynamics, 19(3), 170179.

19. Eken, S., 2019. Free Vibration Analysis of Composite Aircraft Wings Modeled as ThinWalled Beams with NACA Airfoil Sections. Thin-Walled Structures, 139, 362-371.

20. Viglietti, A., Zappino, E., Carrera, E., 2019. Free Vibration Analysis of Variable Angle-tow Composite Wing Structures. Aerospace Science and Technology, 92, 114-125.

21. Wang, A., Ouyang, H., Xie, H., Wu, Y., 2019. Experimental Investigation on a Single NACA Airfoil's Nonlinear Aeroelasticity in Wake Induced Vibrations. Fluid Dynamics, 54(4), 535-549.

22. Bogrekci, I., Demircioglu, P., Sucuoglu, H.S., Guven, E., Demir, N., Durakbasa, M.N., 2019. Structural and Modal Analyses of NACA 66206 Aircraft Wing Model. Proceedings of the International Symposium for Production Research.

23. Kulshreshtha, A., Gupta, S.K., Singhal, P., 2020. FEM/CFD Analysis of Wings at Different Angle of Attack. Materials Today: Proceeedings, 26(2), 1638-1643.

24. Triet, N.M., Viet, N.N., Thang, P.M., 2015. Aerodynamic Analysis of Aircraft Wing. VNU Journal of Science: Mathematics-physics, 31(2), 68-75.

25. Perera, M., He, Y., Guo, S., 2010. Structural and Dynamic Analysis of a Seamless Aeroelastic Wing. $51^{\text {st }}$ AIAA/ASME/ASCE/AHS/ASC Structures, Structural Dynamics, and Materials Conference, 12 April 2010-15 April 2010, Orlando, Florida.

26. Perera, M., Guo, S., 2009. Optimal Design of an Aeroelastic Wing Structure with Seamless Control Surfaces. Proceedings of the Institution of Mechanical Engineers, Part G: Journal of Aerospace Engineering, 223(8), 1141-1151.

27. Newman, J.C., Newman, P.A., Taylor, A.C., Hou, G.J.W., 1999. Efficient Nonlinear Static
Aeroelastic Wing Analysis. Computers \& Fluids, 28, 615-628.

28. Alyanak, E.J., Pendleton, E., 2014. A Design Study Employing Aeroelastic Tailoring and an Active Aeroelastic Wing Design Approach on a Tailless Lambda Wing Configuration, $15^{\text {th }}$ AIAA/ISSMO Multidisciplinary Analysis and Optimization Conference, 16-20 June 2014, Atlanta, GA.

29. Hou, G., Satyanarayana, A., 2000. Analytical Sensitivity Analysis of a Static Aeroelastic Wing. $8^{\text {th }}$ Symposium on Multidisciplinary Analysis and Optimization. Long Beach, CA, U.S.A. 2000.

30. Reich, G.W., Raveh, D.E., Zink, P.S., 2004. Application of Active-aeroelastic-wing Technology to a Joined-wing Sensorcraft. Journal of Aircraft, 41(3), 594-602.

31.Zink, P.S., Raveh, D.E., Mavris, D.N., 2004. Robust Structural Design of an Active Aeroelastic Wing with Maneuver Load Inaccuracies. Journal of Aircraft, 41(3), 585-593.

32. Guo, S., 2007. Aeroelastic Optimization of an Aerobatic Aircraft Wing Structure. Aerospace Science and Technology, 11, 396-404.

33. Stanford, B.K., 2016. Static and Dynamic Aeroelastic Tailoring with Variable-camber Control. Journal of Guidance, Control, and Dynamics, 39(11), 2522-2534.

34. Szollosi, A., Baranyi, P., 2017. Improved Control Performance of the 3-Dof Aeroelastic Wing Section: A Tip Model Based 2d Parametric Control Performance Optimization. Asian Journal of Control, 19(2), 450-466.

35. Abbott, I.H., Von Doenhoff, A.E., 1959. Theory of Wing Sections-including a Summary of Airfoil Data, Dover Publications, New York.

36. Haque, M.N., Ali, M., Ara, I., 2015. Experimental Investigation on the Performance of NACA 4412 Aerofoil with Curved Leading Edge Planform. Procedia Engineering, 105, 232-240.

37. Yagmur, S., Dogan, S., Aksoy, M.H., Goktepeli, I., 2020. Turbulence Modeling Approaches on Unsteady Flow Structures around a Semicircular Cylinder. Ocean Engineering, 200, 107051 . 
38. McAlister, K.W., Takahaski, R.K., 1991. NACA 0015 Wing Pressure and Trailing Vortex Measurements, NASA Technical Paper 3151.

39. Rubel, R.I., Uddin, M.K., Islam, M.Z., Rokunuzzaman, M., 2017. Comparison of
Aerodynamics Characteristics of NACA 0015 \& NACA 4415 Aerofoil Blade. International Journal of Research-granthaalayah, 5(11), 187-197.

\begin{tabular}{|c|c|c|c|c|c|c|c|c|}
\hline \multicolumn{9}{|c|}{ APPENDIX A } \\
\hline \# & $\mathrm{X}$ & $\overline{\mathrm{Y}}$ & \# & $\mathrm{X}$ & $\overline{\mathrm{Y}}$ & \# & $\mathrm{X}$ & $\overline{\mathrm{Y}}$ \\
\hline 1 & 0.249625515 & 0.00499355 & 41 & -0.17454 & 0.054847 & 81 & -0.11134 & 0.001335 \\
\hline 2 & 0.23884796 & 0.004754103 & 42 & -0.18484 & 0.051647 & 82 & -0.10032 & 0.004053 \\
\hline 3 & 0.228069021 & 0.004927897 & 43 & -0.19504 & 0.048174 & 83 & -0.08918 & 0.00619 \\
\hline 4 & 0.21730251 & 0.005475955 & 44 & -0.20521 & 0.044581 & 84 & -0.07794 & 0.007822 \\
\hline 5 & 0.206558323 & 0.006360593 & 45 & -0.21538 & 0.04102 & 85 & -0.06666 & 0.009037 \\
\hline 6 & 0.195843064 & 0.007545964 & 46 & -0.22562 & 0.037639 & 86 & -0.05534 & 0.009887 \\
\hline 7 & 0.185160653 & 0.008998341 & 47 & -0.23596 & 0.034591 & 87 & -0.044 & 0.010404 \\
\hline 8 & 0.174512856 & 0.010686216 & 48 & -0.24643 & 0.032039 & 88 & -0.03265 & 0.010606 \\
\hline 9 & 0.163899747 & 0.012580261 & 49 & -0.25266 & 0.03077 & 89 & -0.0213 & 0.010503 \\
\hline 10 & 0.153320088 & 0.014653203 & 50 & -0.25878 & 0.029013 & 90 & -0.00995 & 0.010098 \\
\hline 11 & 0.142771638 & 0.016879657 & 51 & -0.26474 & 0.026789 & 91 & 0.001375 & 0.009392 \\
\hline 12 & 0.132251398 & 0.019235922 & 52 & -0.2705 & 0.024107 & 92 & 0.012684 & 0.008418 \\
\hline 13 & 0.121755814 & 0.021699769 & 53 & -0.27603 & 0.020965 & 93 & 0.023973 & 0.007224 \\
\hline 14 & 0.111280926 & 0.024250233 & 54 & -0.28126 & 0.017352 & 94 & 0.035241 & 0.005855 \\
\hline 15 & 0.100822494 & 0.026867398 & 55 & -0.28612 & 0.013245 & 95 & 0.046492 & 0.004348 \\
\hline 16 & 0.090376092 & 0.029532207 & 56 & -0.29048 & 0.008615 & 96 & 0.057729 & 0.002742 \\
\hline 17 & 0.079937189 & 0.032226261 & 57 & -0.29415 & 0.003432 & 97 & 0.068958 & 0.001075 \\
\hline 18 & 0.069501215 & 0.034931644 & 58 & -0.29687 & -0.00231 & 98 & 0.080183 & -0.00061 \\
\hline 19 & 0.059063616 & 0.037630747 & 59 & -0.29822 & -0.00851 & 99 & 0.091412 & -0.00227 \\
\hline 20 & 0.048619908 & 0.0403061 & 60 & -0.29771 & -0.01482 & 100 & 0.102655 & -0.00384 \\
\hline 21 & 0.038165727 & 0.04294021 & 61 & -0.29513 & -0.0206 & 101 & 0.113921 & -0.00523 \\
\hline 22 & 0.027696888 & 0.04551541 & 62 & -0.29086 & -0.02528 & 102 & 0.125221 & -0.00631 \\
\hline 23 & 0.017209442 & 0.048013705 & 63 & -0.28551 & -0.0287 & 103 & 0.136551 & -0.00698 \\
\hline 24 & 0.006699748 & 0.050416625 & 64 & -0.27959 & -0.031 & 104 & 0.1479 & -0.00723 \\
\hline 25 & -0.003835443 & 0.052705085 & 65 & -0.27338 & -0.03236 & 105 & 0.159249 & -0.00706 \\
\hline 26 & -0.01439889 & 0.054859253 & 66 & -0.26704 & -0.03293 & 106 & 0.170591 & -0.00659 \\
\hline 27 & -0.024992737 & 0.056858421 & 67 & -0.26069 & -0.03284 & 107 & 0.181925 & -0.00597 \\
\hline 28 & -0.035618375 & 0.058680905 & 68 & -0.25436 & -0.03216 & 108 & 0.193261 & -0.00538 \\
\hline 29 & -0.046276263 & 0.060303953 & 69 & -0.24305 & -0.03126 & 109 & 0.204603 & -0.00491 \\
\hline 30 & -0.056965728 & 0.061703697 & 70 & -0.23175 & -0.03015 & 110 & 0.215951 & -0.00464 \\
\hline 31 & -0.067684733 & 0.062855145 & 71 & -0.22048 & -0.02881 & 111 & 0.227302 & -0.00457 \\
\hline 32 & -0.078429611 & 0.063732242 & 72 & -0.20925 & -0.02718 & 112 & 0.238653 & -0.0047 \\
\hline 33 & -0.08919478 & 0.064308005 & 73 & -0.19806 & -0.02523 & 113 & 0.25 & -0.00501 \\
\hline 34 & -0.09997244 & 0.064554777 & 74 & -0.18695 & -0.02292 & 114 & 0.25196 & -0.00461 \\
\hline 35 & -0.110752284 & 0.064444594 & 75 & -0.17593 & -0.02019 & 115 & 0.253607 & -0.00347 \\
\hline 36 & -0.121521244 & 0.063949713 & 76 & -0.16503 & -0.01703 & 116 & 0.254678 & -0.00179 \\
\hline 37 & -0.132263307 & 0.063043288 & 77 & -0.15425 & -0.01346 & 117 & 0.255004 & 0.000187 \\
\hline 38 & -0.142959463 & 0.061700203 & 78 & -0.14358 & -0.00961 & 118 & 0.254532 & 0.002131 \\
\hline 39 & -0.153587817 & 0.059898022 & 79 & -0.13293 & -0.00568 & 119 & 0.253337 & 0.003734 \\
\hline 40 & -0.164123926 & 0.057618004 & 80 & -0.12221 & -0.00195 & 120 & 0.251609 & 0.004742 \\
\hline
\end{tabular}


